\title{
The Effectiveness of Materials Different with Regard to Increasing the Durability
}

\author{
Vladimir Erofeev ${ }^{1,}{ }^{*}$, Anna Dergunova ${ }^{1}$, Anna Piksaikina $^{1}$, Andrey Bogatov ${ }^{1}$, Evgeny \\ $\mathrm{Kablov}^{2}$, Oleg Startsev ${ }^{2}$, and Aleksandr Matvievskiy ${ }^{3}$ \\ ${ }^{1}$ Ogarev Mordovia State University, 430005 Saransk, Russian Federation \\ ${ }^{2}$ All-Russian scientific research institute of aviation materials, 105005 Moscow, Russian Federation \\ ${ }^{3}$ Maxmir' Open Joint-Stock Company, 121099 Moscow, Russian Federation
}

\begin{abstract}
The article considers contemporary materials and structures for construction of buildings. The article conducts an economic study of the problem of durability. It addresses the issue of increasing longevity, affecting the term of service to building structures and the efficiency of their operation. Revealed the main factors affecting the durability. It identifies measures its realisation. The method of calculation of economic efficiency of improving the durability of building constructions.
\end{abstract}

\section{Introduction}

Recently, in connection with the acceleration of introduction of scientific and technical progress, an increasing attention is paid to the introduction of new aircraft, industrial, electrical and construction materials and increasing of durability of machines, units, buildings and structures, as the most important indicators of the quality of industrial products.

Assessment of the level material allows to accurately set the relationship between the quantity produced in a particular product and indirect costs in material resources, as well as to evaluate the rationality of the latter. The indicator reflects the impact of increased material costs associated with the modernization of the production process, the production and the efficiency of economic activity in general.

The reduction of the material production is an important direction of increasing of economic efficiency of production as the economical use of energy and material resources ensures the continuous growth of output and reduction of production costs. Conservation of resources has become a crucial source to meet the growing needs of the country in raw materials, materials, fuel, energy.

\section{Materials and Methods}

In many sectors of the economy, reduction in material costs is achieved by the development and use of more economical types of products, materials and constructions, machines and

* Corresponding author: erofeev.vt@yandex.ru 
mechanisms. Reduction of weight characteristics of machinery and equipment without compromising quality an indicator of their high technical level, deepening the intensification of production.

One of the ways to reduce material intensity is the use of progressive types of material resources: composite materials, metal powders, polymers, plastics and etc. Their application makes it possible not only to reduce the cost of raw materials, but also reduce the complexity of products, increase the loading of equipment. The important reserve of reduction of the material production is the organization of process stages, for example, rational cutting of metal and wood, as well as reduction of scraps and waste. This facilitates the introduction of advanced technological processes, increasing technological discipline, improving the organization of production and labor [1].

The annual economic effect of reducing the material intensity by two options of production, with a planned amount of output is determined by the formula:

$$
E_{g}=\left(\left(S_{b}+E_{n} \cdot K_{b}\right)-\left(C_{2}+E_{n} \cdot K_{2}\right)\right) \cdot Q
$$

where $\mathrm{Sb}$ - unit cost of the product when using technology in the base case; En - norm of efficiency; $\mathrm{Kb}$ - the specific capital investments using basic equipment option; $\mathrm{C} 2$ - unit cost of the product when using the technique in the second embodiment; K2 - specific capital costs when using technology of the second option; Q - volume of the planned products.

Durability is a property of a system to remain operational until the occurrence of the limit state with the necessary interruptions for maintenance and repairs. The limiting condition is determined by technical impossibility or inexpediency of further operation of the system and is caused by safety requirements or a permanent reduction in the efficiency [1].

Overall durability of industrial products is determined by economically optimal lifespan, representing a calendar time, during which their maintenance is economically justified and safe.

Durability has a huge impact on the efficiency of operation of devices, apparatuses, components and structures. For its estimation the most commonly used technical and economic indicators. Durability affects the level of national economic costs both in manufacturing and in the field of consumer products. Increase the durability of any items pushes the beginning of repairs by the consumer in their recovery and may extend the economic life of manufactured products. In the production of devices, apparatus, components and structures measures to improve the durability, usually require an additional one-off and ongoing costs at the same time by improving the durability may be reduced demand for its products, which in General leads to savings in capital investments for their creation. The impact of longevity on the scale of need for them is manifested through the change of life. The higher the economically optimum service life of the devices, apparatus, components and structures, the less the need for them.

Durability, having a major impact on the efficiency of the production and use of industrial products, in turn, depends on many factors acting at all stages: design, manufacturing and operation.

At the design stage the main factors influencing durability include:

- constructive decisions;

- selection of materials;

- production technology.

At the manufacturing stage there are the following factors, influenced on durability:

- level of technology, technology and culture of production;

- technological discipline; 
- the quality of the materials and components used in the manufacture of apparatus, devices, products and constructions and their elements;

- the current output and quality control.

At the stage of operation the level of durability laid in the previous stages is realized, and it depends on the following factors:

- adherence to prescribed operation modes;

- level of qualification and discipline of staff;

- the quality of preventive maintenance;

- natural aging of the component parts of apparatus, instruments, products and structures;

- the state of the external environment in which products operate and design.

In domestic and world practice great attention is paid to improving the durability of the materials, industrial, aviation, electrical and construction purposes, operating in conditions of biological aggression. For further consideration of a large range of industrial materials select building materials and building structures on their basis.

Biological damage of building structures is one of the basics external factors that determines the rate of depreciation of buildings and other engineering structures (along with exposure to aggressive gases, acid rain, freezing, weathering, etc.) [2-16].

In the design and construction of industrial buildings and structures exposed to the biodestructors, you must strive to ensure that by appropriate measures for the protection of building structures from biological damage to ensure the smooth operation of basic funds of enterprises within the regulatory period of service [3]. This can be achieved by applying the following measures to protect against destroying structures [17-24]:

- creation and implementation of building materials and structures having improved resistance to biological damage;

- application of protective coatings or special additives;

- develop constructive measures of protection against biological damage;

- design and implementation of measures to protect against biological damage, carried out in the manufacture of building products and components intended for use in aggressive environment;

- design and implementation of projects constructed of materials resistant to the effects of biodestructors.

Activities to increase longevity are very diverse, and cost of holding are formed from the funds allocated for these purposes at all stages of the life cycle of structures. The cost required for increasing the input current and of quality control; the purchase of more expensive, but more reliable components and materials; the use of new constructive and technological solutions; stimulate training of employees; use of new equipment and production technologies; maintaining an economically optimal amount of redundant and spare components (blocks and units), etc [25-32].

Activities to improve the durability, from the point of view of economic efficiency, should be divided into two groups, each of which you can specify some features of the calculation of national economic benefits. The first group will be assigned those that are reduced to enhance durability of building structures and will not change the found for the building or facility the economically optimal lifespan. The commitment of this group of activities is quite legitimate, despite the fact that theoretically the durability (resource) of any element involved in the formation of optimal service life of buildings and structures. The fact is that not every increase of one resource element has such a significant effect on technical and economic parameters to "offset" the optimal lifetime. You must keep in mind the fact that the definition of economically optimal timing of service is based on anticipation of future changes in techno-economic parameters, which lead to its moral 
depreciation and impairment losses. Therefore, all qualitative changes of the elements are already accounted for.

The second group of measures for increasing longevity are those whose implementation leads to increased lifetime of buildings and structures. Included among the activities for the components and subsystems of complex structural systems, durability which limits their lifespan.

When the events of the first group, the economic effect can be obtained only when the service life of buildings and structures reduce the number and duration of works to restore and replacement of those elements that have promoted the resource. Savings resulting from this should exceed the growth in the value of elements that are part of buildings and constructions and used when conducting planned repairs (replacements).

\section{Results and Discussion}

In determining the boundaries of economically feasible improvement of durability should start from the optimal system repair, which under the influence of an increase in resource groups of elements can be changed so that there will be the task of the next optimization. Therefore, the problem of evaluating economic efficiency of increasing the longevity of one element cannot be viewed in isolation from other elements and the corresponding system of repair of the building or structure [25-29].

Clearly ineffective interventions include those that do not reduce through a number of planned replacements of elements. Denoting the number of planned replacements to increase longevity as ns, we have:

$$
n_{s}=T_{s} / t_{0}
$$

where $T_{\mathrm{S}}$ - the service life, years; $t_{0}-$ the average life of components to enhance durability.

Here it is clearly inefficient for the building or structure to measures to increase longevity are those for which

where $t_{1}$ - average of service life after improve the durability; $n_{\mathrm{p}}$ - the number of planned replacements of elements after increasing durability.

If the number of planned replacements of elements reduces the result of an increase in resource, and the total number of scheduled repairs remains unchanged, i.e. under conditions

$$
n_{\mathrm{p}}<n_{\mathrm{s}}, N_{\mathrm{n}}=N_{\mathrm{s}}
$$

where $N_{\mathrm{s}}$ and $N_{\mathrm{n}}$ is the number of scheduled repairs (replacements) of the elements of the design of structures for the service life before and after improve the durability of one of the groups of elements, in the sphere of consumption must increase prices because of increased longevity be compared with possible savings by reducing the number of planned replacements. Subject to the terms of the data saving from the use of more durable elements, in essence, boils down to cost savings on their purchase. This should include not only the cost of planned replacements (repairs) elements, but also their value, which is equal to the product of the number of items and their wholesale prices. Hence, taking into account the time factor, approximately the expenses of the consumers on the elements before and after to enhance their durability are defined by the formulas:

$$
C_{\mathrm{s}}=\left(n_{\mathrm{s}}+1\right) P_{\mathrm{s}} \beta_{\mathrm{e}}+n_{\mathrm{s}}\left(C_{\mathrm{r}}+C_{\mathrm{v}}\right)
$$




$$
C_{\mathrm{n}}=\left(n_{\mathrm{n}}+1\right) P_{\mathrm{n}} \beta_{\mathrm{e}}+n_{\mathrm{n}}\left(C_{\mathrm{r}}+C_{\mathrm{v}}\right),
$$

where $P_{\mathrm{s}}$ and $P_{\mathrm{n}}$ - wholesale price of one of the element respectively before and after the increase its durability; $\beta_{\mathrm{e}}$ - the number of elements contained in the technical system; $C_{\mathrm{r}}$ - expenses for registration and issuance of one purchase order and receive the items for replacement from the supplier; $C_{\mathrm{V}}$ - expenses for the planned replacement of elements without regard to their value.

The difference between costs before and after increasing their durability represents the magnitude of the economic effect of increasing durability:

$$
E_{\mathrm{i}}=C_{\mathrm{s}}-C_{\mathrm{n}}
$$

In accordance with this economically all options for increasing durability of elements justified are:

$$
C_{\mathrm{s}}-C_{\mathrm{n}}>0 \text {. }
$$

The savings of the consumer is formed by reducing the number of planned replacements and repairs.

For the general case, this savings is defined as the sum of cost savings by the consumer as a result of reducing the number of planned replacements and repairs of items, i.e.

$$
E_{\mathrm{n}}=\left(n_{\mathrm{s}}-n_{\mathrm{n}}\right)\left(P_{\mathrm{s}} \beta_{\mathrm{e}}+C_{\mathrm{r}}+C_{\mathrm{v}}\right)=\Delta n C_{\mathrm{s}}
$$

where $\Delta n=n_{\mathrm{s}}-n_{\mathrm{n}}$.

Improve the durability, usually accompanied by rising costs in production, as a result of increased price leading to increased costs. Additional costs to the consumer in this regard, in the general case will be:

$$
C_{\mathrm{p}}=\left(n_{\mathrm{n}}+1\right)\left(C_{\mathrm{n}}+C_{\mathrm{s}}\right) \beta_{\mathrm{e}}
$$

It follows that the magnitude of the economic effect of the improvement of durability can also be determined in the form:

$$
E_{\mathrm{i}}=E_{\mathrm{n}}-C_{\mathrm{p}}
$$

$$
C_{\mathrm{s}}-C_{\mathrm{n}}=E_{\mathrm{n}}-C_{\mathrm{p}}
$$

The factor of time influences the magnitude of the economic effect of the time difference and cost savings from better resource. It is more correct to speak about the time difference just cost, since they are primary, and the economy and the secondary effect.

The factor of time affects the dynamics of the economic effect thus:

- leads to narrow the range of cost-effective solutions when increasing durability of elements;

- supports absolute and relative decrease in the economic effect.

When carrying out the activities to improve the durability of the economic effect can be achieved by increasing of service life of building structures. The formula for calculating the economic benefit of increased service life is as follows:

$$
E_{\mathrm{n}}=\left(C_{\mathrm{s}} K_{\mathrm{c}} K_{\mathrm{s}}+\Delta E_{\mathrm{m}}-C_{\mathrm{n}}\right) V_{\mathrm{n}},
$$


where $K_{\mathrm{c}}$ - coefficient accounting for changes in performance as a result of increasing longevity; Ks - the factor of life; $\Delta E_{\mathrm{m}}$ - economic effect, which is formed by the lower costs of resources in the process of operation, more durable building structures; $V_{\mathrm{n}}-$ annual production of new building structures in natural units.

When the same depreciation rates factor change of life is determined by the formula:

$$
K_{\mathrm{s}}=\left(N_{\mathrm{o}}+Z\right) /\left(N_{\mathrm{n}}+Z\right),
$$

where $N_{\mathrm{o}}$ and $N_{\mathrm{n}}$ - norm of depreciation charges on full restore set respectively the old and new designs in fractions of a unit; $Z$ - the coefficient of efficiency of capital investments equal to the annual interest rate.

\section{Summary}

Studies have shown that the evaluation of the effectiveness of measures to improve structural durability could be guided not only on the change in costs of production, but also from the standpoint of the individual consumer. And in different cases the measurement of effectiveness involves a comparison of costs before and after improvement of durability.

\section{References}

1. N. P. Makarkin, Economics of reliability engineering (Publishing Economics, Moscow, 2001)

2. V. T. Erofeev, Microbiological degradation of materials (Moscow, 2008)

3. V. T. Erofeev, Protection of buildings and structures from microbiological damage of biocidal preparations on the basis of guanidine. Monography (St. Petersburg, 2009)

4. V. I. Solomatov, V. T. Erofeev, V. F. Smirnov, A. S. Semicheva, E. A. Morozov, Bio logical mechanics of materials (Saransk, 2001)

5. V. T. Erofeev, Frame building composites. The dissertation on competition of a scientific degree of the doctor of technical Sciences (Moscow, 1993)

6. V. F. Smirnov, D. A. Svetlov, S. V. Kaznacheev, A. D. Bogatov, E. A. Morozov, O. D. Vasiliev, Y. M. Makarevich, V. A. Spirin, N. A. Patsyuk, Protection of buildings and structures from microbiological damage of biocidal preparations on the basis of guanidine (St. Petersburg, 2009)

7. V. T. Erofeev, V. F. Smirnov, Microbiological degradation of materials (Moscow, 2008)

8. D. A. Svetlov, V. A. Spirin, S. V. Kaznacheev, A. D. Bogatov, A. S. Boriskin, V. T. Erofeev, Transport construction, 2, 21-23 (2008)

9. V. T. Erofeev, A. I. Rodin, A. D. Bogatov, S. V. Kaznacheev, V. F. Smirnov, E. N. Suraeva, M. A. Rodina, International Journal for Computational Civil and Structural Engineering, 3, 81-92 (2012)

10. V. T. Erofeev, V. F. Smirnov, I. E. Kondakova, S. V. Kaznacheev, A. D. Bogatov, Izvestiya of the Tula state University. Technical Sciences, 7-2, 310-325 (2013)

11. V. T. Erofeev, V. F. Smirnov, S. N. Bogatova, A. A. Bogatov, S. V. Kaznacheev, Bulletin of Volgograd state University of architecture and construction. Series: Construction and architecture, 16, 122-126 (2009)

12. V. T. Erofeev, A. I. Rodin, A. D. Bogatov, S. V. Kaznacheev, V. F. Smirnov, D. A. Svetlov, News of the Tula state University. Technical Sciences, 7-2, 292-310 (2013) 
13. V. T. Erofeev, S. V. Kaznacheev, A. D. Bogatov, V. A. Spirin, D. A. Svetlov, S. N. Bogatova, Bulletin of the Dagestan state technical University. Technical Sciences, 26, 108-113 (2012)

14. V. T. Erofeev, A. D. Bogatov, S. N. Bogatova, V. F. Smirnov, News of Kazan state University of architecture and construction, 2(14), 21-217 (2010)

15. V. T. Erofeev, A. D. Bogatov, V. F. Smirnov, S. N. Bogatova, S. V. Kaznacheev, A. I. Rodin, Proceedings of the International scientific-technical conference named after Leonardo da Vinci, 1, 83-97 (2013)

16. V. T. Erofeev, E. N. Suraeva, , A. A. Bogatov, S. V. Kaznacheev, V. F. Smirnov, A. I. Rodin, International Journal for Computational Civil and Structural Engineering, 8, 93$100(2012)$

17. M. M. Kacimkina, D. A. Svetlov, S. V. Kaznacheev, A. D. Bogatov, A. S. Boriskin, V. T. Erofeev, Transport construction, 2, 29-30 (2009)

18. M. E. Bazhanova, V. T. Yerofeev, A. N. Bobryshev, News of southwest state University, 5-2(38), 415-421 (2011)

19. E. V. Zavalishin, V. T. Erofeev, V. F. Smirnov, E. A. Morozov, Materials of the International scientific-technical conference, 156-159 (2004)

20. V. T. Erofeev, A. D. Bogatov, S. N. Bogatova, V. F. Smirnov, E. A. Zakharova, Vestnik of Volgograd state University of architecture and construction. Series: Construction and architecture, 22, 73-78 (2011)

21. M. E. Bazhanova, V. T. Erofeev, Belgorod state technological University, 1, 31-33 (2012)

22. S. V. Houtorskoy, V. T. Erofeev, V. F. Smirnov, News of Kazan state University of architecture and construction, 2(24), 281-286 (2013)

23. V. T. Erofeev, A.V. Dergunova, Building materials, 2, 88-89 (2008)

24. A. V. Dergunova, V. T. Erofeev, V. F. Smirnov, Biodeterioration of biological corrosion and in the construction materials of the Third International scientifictechnical conference. Russian Academy of architecture and construction Sciences, 285$288(2009)$

25. A.V. Dergunova, A. D. Bogatov, V. T. Erofeev, Biodeterioration biological corrosion and in the construction materials of the Third International scientific-technical conference. Russian Academy of architecture and construction Sciences, 281-284 (2009)

26. V. T. Erofeev, V. F. Smirnov, N. V. Cherushova, E. A. Mitina, O. N. Smirnova, News of higher educational institutions. Construction, 2, 36-41 (2003)

27. A. V. Dergunova, A. D. Bogatov, V. T. Erofeev, Biodeterioration biological corrosion and in construction: proceedings of the third international scientific-technical conference, 277-281 (2009)

28. V. T. Erofeev, A.V. Dergunova, Building materials, 2, 88-89 (2008)

29. A.V. Dergunova, Actual problems of architecture and construction: proceedings of the eleventh international scientific.-tech. Conf., 352-355 (2009)

30. R. Usmanov, V. Murgul, N. Vatin, Applied Mechanics and Materials, 633-634, 1082$1085(2014)$

31. I. Mrdak, M. Rakočević, L. Žugić, R. Usmanov, V. Murgul, N. Vatin, Applied Mechanics and Materials, 633-634, 1069-1076 (2014)

32. R. Usmanov, M. Rakočević, V. Murgul, N. Vatin, Applied Mechanics and Materials, 633-634, 927-931 (2014) 